\title{
Profil Kecenderungan Gaya Belajar Mahasiswa Semester Awal Jurusan Pendidikan Biologi Fakultas Keguruan dan Ilmu Pendidikan Universitas Borneo Tarakan
}

\section{The Learning Style Profile of Early Semester Students in Biology Education Department at Faculty of Teacher Training and Education University Borneo Tarakan}

\author{
Aidil Adhani ${ }^{a^{*}}$ \\ Jurusan Pendidikan Biologi, FKIP, Universitas Borneo Tarakan, Tarakan, Indonesia \\ ${ }^{*}$ Corresponding author: Jl. Amal Lama, Tarakan Timur, Tarakan, Kalimantan Utara, 77123, Indonesia. E-mail: adhani89@gmail.com
}

\begin{abstract}
Abstrak
Mahasiswa merupakan kumpulan individu dengan berbagai karakter. Salah satu karakter yang bisa dibedakan adalah gaya belajarnya. Gaya belajar merupakan kebiasaan belajar yang disenangi oleh mahasiswa untuk mempermudah mempelajari topik perkuliahan. Tujuan dari penelitian ini yaitu untuk mengetahui kecenderungan gaya belajar mahasiswa baru jurudan Pendidikan biologi FKIP UBT agar dosen dapat memfasilitasi dengan baik kebutuhan belajar mahasiswa. Penelitian ini merupakan penelitian deskriptif kualitatif dengan menggunakan angket gaya belajar sebagai instrument penelitian. Hasil analisis data menujukkan bahwa persentase gaya belajar visual $(46,67 \%)$, auditorial $(30 \%)$, kinestetik $(8,33 \%)$, visual-auditorial $(11,67)$, dan visual kinestetik $(3,33 \%)$. Kecenderungan gaya belajar mahasiswa yang dominan yaitu visual dan yang persentase terendah yaitu gaya belajar kinestetik.
\end{abstract}

\section{Kata kunci}

Auditorial, kinestetik, learning style, mahasiswa, visual

\begin{abstract}
Students are a group of individuals with various characters. One of the distinguishing characteristics is the learning style. Learning styles are learning habits that are liked by students to make it easier to learn lecture topics. The purpose of this study was to determine the learning styles of Early semester students in the Biology Education Department FKIP UBT for the lecturers could properly facilitate student learning needs. This research is a qualitative descriptive study using a learning style questionnaire as a research instrument. The results of data analysis showed that the percentage of learning styles was visual (46.67\%), auditory (30\%), kinesthetic (8.33\%), visual-auditory (11.67), and visual kinesthetic (3.33\%). The dominant student learning style preference is visual and the lowest percentage is kinesthetic learning style.
\end{abstract}

\section{Keywords}

Auditory, kinesthetic, learning style, students, visual. 


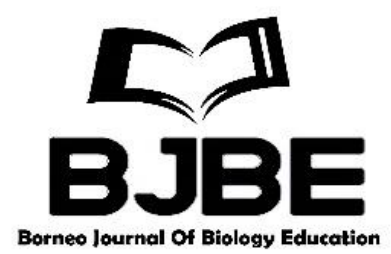

Vol. 2 No. 1, 2020; pp. 1-6

P-ISSN: 2715-6826 (print); E-ISSN: 2714-6073 (online)

Received: 25/01/2020

Revised: 15/02/2020

Accepted: 3/03/2020

\section{Pendahuluan}

Mahasiswa merupakan kumpulan individu dengan berbagai karakter. Karakter yang dimiliki oleh mahasiswa merupakan hal yang perlu diperhatikan oleh pendidik, dalam hal ini dosen. Dosen perlu mengetahui bahkan menelaah lebih jauh karakter yang heterogen tersebut sehingga mampu membelajarkan mahasiswa secara optimal. Belajar merupakan perubahan tingkah laku yang dapat terukur dan sifatnya permanen. Proses belajar mengajar menjadi kunci utama tercapainya kompetensi-kompetensi yang tertuang dalam rencana pembelajaran. Salah satu hal yang perlu diketahui oleh dosen adalah gaya belajar mahasiswa.

Gaya belajar setiap mahasiswa bisa saja berbeda-beda. Menurut DePorter (2010) gaya belajar adalah kombinasi dari bagaimana peserta didik menyerap, kemudian mengatur serta mengolah informasi yang diterima. Dalam artian sempit, gaya belajar merupakan kebiasaan belajar yang disenangi oleh mahasiswa untuk mempermudah mempelajari topik perkuliahan. Gaya belajar tertentu akan mendominasi setiap mahsiswa dan menjadi pembeda antara mahasiswa satu dengan lainnya. Kecenderungan gaya belajar mahasiswa secara umum dapat dibagi menjadi tiga jenis, yaitu visual, auditorial, dan kinestetik (VAK). Meskipun pada kenyataannya, gaya belajar tersebut bisa saja merupakan kombinasi dari jenis-jenis gaya belajar utama yang disebutkan sebelumnya.

Julianti (2016) menjelaskan bahwa individu yang memiliki kecenderunagn belajar visual lebih senang dengan melihat apa yang sedang dipelajari. Simbol atau gambar akan sangat membantu mereka untuk lebih memahami ide atau informasi yang diperoleh. Individu yang memiliki kecenderungan gaya belajar auditorial lebih senang mendengarkan apa yang disampaikan orang lain. Gaya belajar ini lebih menempatkan pendengaran sebagai alat memperoleh informasi. Individu yang memiliki kecenderunagan gaya belajar kinestetik akan lebih baik terlibat secara fisik dalam kegiatan langsung atau yang banyak melibatkan aktivitas fisik.

Pentingnya menganalisis gaya belajar mahasiswa menjadi dasar dalam penelitian ini. Dosen sebagai fasilitator dalam kegiatan belajar mahasiswa perlu mengetahui gaya belajar dari peserta didiknya. Hal tersebut akan lebih efektif jika dosen mengetahui gaya belajar mahasiswa dari awal (mahasiswa baru). Data terkait gaya belajar yang diperoleh dapat membantu dosen dalam membelajarkan mahasiswa sesuai dengan kebutuhan cara belajarnya. Dalam artian, dosen akan mampu merancang pembelajaran yang sesuai bagi mahasiswa, baik dari segi penggunaan model pembelajaran atapun media yang digunakan. Dengan demikian, upaya tersebut dapat menjadi upaya preventif bagi mahasiswa baru untuk mengatasi ketidaksesuaian cara belajar yang diterima selama menempuh jenjang perkuliahan.

\section{Material dan metode}

Penelitian ini merupakan penelitian kuliatitaif dengan metode analisis deskriptif dengan tujuan untuk memperoleh gambaran empiris mengenai keadaan yang sedang berlangsung pada saat penelitian ini dilaksanakan. Populasi dalam penelitian ini adalah seluruh mahasiswa baru jurusan Pendidikan biologi tahun akademik 2020/2021 yang terdiri dari 60 mahasiswa. 


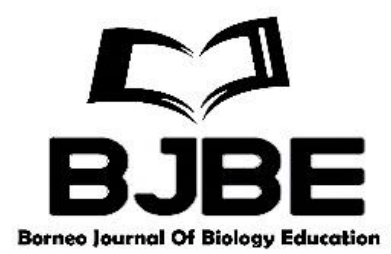

Penentuan sampel menggunakan teknik sampling jenuh, artinya seluruh populasi menjadi anggota sampel.

Analisis data yang digunakandalam penelitian ini yaitu analisis deskriftif kualitatif. Data yang dianalisis dalam penelitian ini yaitu data gaya belajar visual, auditorial dan kinestetik. Tahapan dalam analisis data meliputi pengumpulan data, reduksi data, penyajian data, dan penarikan kesimpulan. Instrumen pengumpulan data yang digunakan adalah instrument berupa angket yang penyataannya mewakili gaya belajar visual, auditorial dan kinestetik. Untuk menganalisa data dalam penelitian ini digunakan teknik persentase dengan rumus :

$$
P=\frac{F}{N} \times 100 \%
$$

Dimana:

$\mathrm{P}=$ Persentase

$\mathrm{F}=$ Frekuensi

$\mathrm{N}=$ Jumlah data

\section{Hasil dan Diskusi}

Profil kecenderungan gaya belajar mahasiswa baru jurusan Pendidikan biologi diperoleh melalui pemberian angket yang terdiri dari tiga aspek utama, yaitu visual, auditorial dan kinestetik. Setiap responden mengisi kuesioner yang berjumlah 15 pernyataan. Skor angket tersebut kemudian dipersentasekan untuk memperoleh gambaran terkait kecenderungan gaya belajar mahasiswa jurusan Pendidikan biologi seperti pada Gambar 1 berikut.

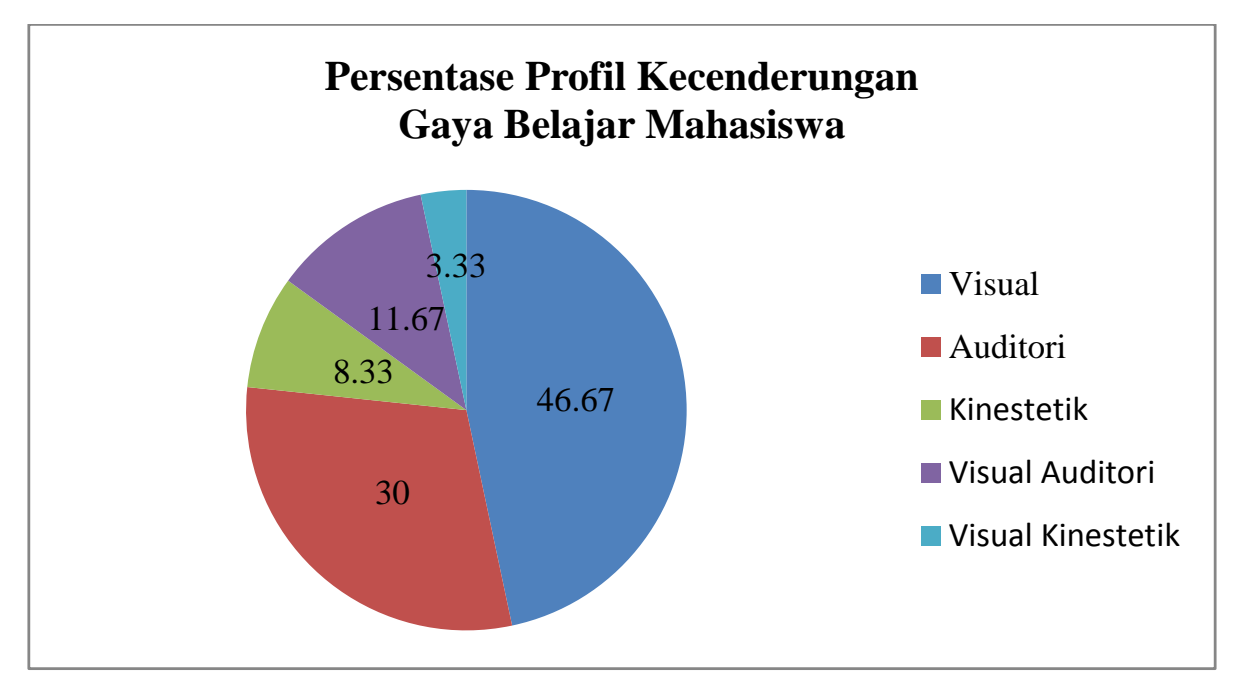

Gambar 1. Persentase profil kecenderungan gaya belajar mahasiswa baru 2020/2021 jurusan Pendidikan Biologi FKIP UBT 


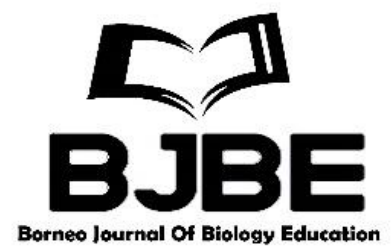

Berdasarkan Gambar 1 tersebut terlihat bahwa selain 3 jenis gaya belajar utama (visual, auditorial, kinestetik), diperoleh pula kombinasi dari gaya belajar tersebut yaitu visual auditorial dan visual kinestetik. Menurut Ghufron dan Risnawita (2013) bahwa setiap individu memiliki ciri khas masing-masing (unik), sehingga tidak ada dua individu yang sama. Dari 6 data kecenderungan gaya belajar yang diperoleh, gaya belajar visual memiliki persentase tertingi. Persentase mahasiswa dengan kecenderungan gaya belajar visual sebesar 46,67\%. Gaya belajar visual merupakan gaya belajar yang mengutamakan pemanfaatan indra penglihatan dibandingkan indra lainnya. Seperti yang diungkapkan oleh Subini (2011) bahwa gaya belajar adalah cara menyerap informasi melalui indra yang kita miliki. Mahasiswa yang memiliki kecenderungan gaya belajar visual lebih senang melihat apa yang sedang dipelajari. Visualisasi akan membantu mereka yang memiliki gaya belajar visual untuk mudah memahami ide atau informasi daripada jika ide atau informasi tersebut disampaikan dalam bentuk penjelasan (Zahroh dan Asyhar, 2014). Berdasarkan data angket yang diperoleh, sebanyak 85\% mahasiswa menyatakan bahwa mereka lebih mudah mengingat materi perkuliahan ketika mencatat materi yang disampaikan oleh dosen dan merasa kesulitan belajar jika tidak membuat catatan tersebut. selain itu, sebanyak $90 \%$ mahasiswa juga menytakan bahwa lebih senang dan mudah memehami bacaan ketika membaca buku teks yang dilengkapi gambar. Hal tersebut senada dengan pendapat Widayah (2016) bahwa kecenderungan gaya belajar visual memperoleh informasi dengan baik dengan melihat gambar, diagram, grafik, poster, dan melihat data teks seperti tulisan atau huruf. Mahasiswa dengan gaya belajar visual memiliki kebutuhan yang tinggi untuk melihat dan menangkap informasi secara visual sebelum mereka mengolah informasi tersebut.

Kecenderungan gaya belajar mahasiswa yang memiliki persentase tertinggi kedua yaitu gaya belajar auditorial yaitu sebesar 30\%. Gaya belajar auditorial ini ditandai oleh pengoptimalan fungsi indra pendengan ketika menerima informasi ataupun mengolah ide baru. Menurut Zahroh dan Asyhar (2014), orang-orang dengan gaya belajar auditorial lebih nyaman dan menikmati saat-saat mendengarkan informasi yang disampaikan oleh orang lain. Hasil analisis angket menunjukkan bahwa 73\% mahasiswa dengan kecenderungan gaya belajar auditorial menyatakan bahwa sangat aktif ketika ada kegiatan diskusi kelas atau kelompok. Selain itu, $80 \%$ mahasiswa auditorial juga menyatakan bahwa mereka lebih mudah memahami penjelasan dari dosen dibandingkan harus membaca buku teks. Oleh karena itu, metode ceramah, tanya jawab, dan diskusi dianggap lebih efektif diterapkan untuk mahasiswa dengan gaya belajar auditorial (Jatikusumo, dkk, 2017). Dalam menyerap informasi umumnya mahasiswa dengan gaya belajar auditorial menerapkan strategi pendengaran yang kuat dengan suara dan ungkapan yang berciri pendengaran. Suparman (2010) melaporkan bahwa kemampuan seseorang dengan gaya belajar auditorial dalam berbicara lebih cepat dan juga cepat mengenal kata-kata baru serta senang bila dibacakan cerita-cerita. Selain itu, mereka akan sangat terganggu untuk belajar ketika kondisi lingkungan atau sekelilingnya ribut. Sehingga, mahasiswa dengan gaya belajar ini akan lebih senang belajar di tempat yang tenang agar bisa fokus.

Hasil analisis data terkait kecenderungan gaya belajar mahasiswa baru dengan tipe kinestitik hanya $8,33 \%$. Hasil ini jauh lebih rendah dibandingkan dua gaya belajar yang dibahas 


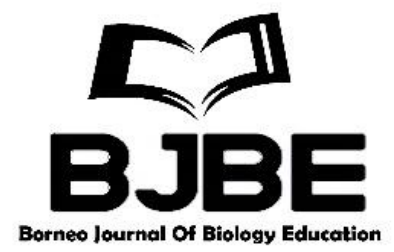

sebelumnya. Gaya belajar kinestetik lebih senang belajar dengan melibatkan aktivitas fisik (bergerak) atau bahkan mencoba melakukan eksperimen untuk memperoleh informasi lebih. Mahasiswa dengan gaya belajar ini menyatakan bahwa mereka merasa lebih mudah menghafalkan materi perkuliahan ketika menghafalkannya sambil berjalan. Sebanyak 70\% mahasiswa dengan kecenderungan gaya belajar ini juga menyatakan bahwa mereka lebih senang belajar ketika ada kegiatan demonstrasi di kelas ataupun dilaboratorium. Menurut Jatikusumo, dkk (2017), mahasiswa tipe kinestetik lebih mudah menangkap dan mengolah informasi melalui sentuhan, gerakan, mengambil tindakan, atau dipraktikkan secara langsung. Mereka akan berhasil dalam belajar apabila memperoleh kesempatan untuk memanipulasi media dalam mempelajari informasi baru (DePorter \& Hernacki, 2009).

Selain ketiga gaya belajar utama yang dibahas, data penelitian juga menunjukkan bahwa ada mahasiswa yang memiliki kecenderungan kombinasi dari dua gaya belajar utama, yaitu visual auditorial dan visual kinestetik. Persentase mahasiswa dengan kecenderungan gaya belajar visual auditorial sebesar 11,67\%. Mahasiswa dengan gaya belajar visual auditorial mengkombinasikan dengan baik kemampuan indera penglihatan dan pendengaran dalam menangkap dan memproses materi perkuliahan yang diterima. Mereka akan mampu belajar dengan baik dengan dengan bantuan gambar (visual) dan mendengarkan ceramah dari dosen. Sedangkan persentase mahasiswa dengan kecenderungan gaya belajar visual kinestetik sebesar $3,33 \%$. Persentase ini jauh lebih rendah dibandingkan persentase gaya belajar lainnya. Mahasiswa dengan kecenderungan visual kinestetik merasa senang belajar ketika mereka melihat dan mempraktekkan apa yang dipelajari.

Belajar adalah kegiatan yang dilakukan secara sadar oleh seseorang. Dalam kegiatan belajar, seseorang menggunakan lebih dari satu panca indra dan pikirannya. Hasil yang diperoleh dari proses belajar disebut dengan hasil belajar. Salah satu faktor penting yang mempengaruhi pencapaian hasil belajar adalah pemahaman akan gaya belajar peserta didik. Setiap individu menggunakan semua indera dalam menyerap informasi. Akan tetapi, secara umum individu mempunyai kecenderungan lebih kuat pada salah satu gaya belajar (DePorter \& Hernacki, 2009). Tidak ada satu cara yang yang paling benar untuk belajar dalam situasi tertentu. Setiap orang memiliki gaya belajarnya sendiri yang juga dapat berbeda dari satu situasi ke situasi lainnya. Karena keragaman teori dan gaya pembelajaran, seseorang dapat memilih strategi dan gaya yang berbeda secara fleksibel dalam berbagai situasi sehingga dapat menggunakan yang paling efisien. Semakin baik seseorang menyadari gaya belajarnya sendiri, semakin baik ia dapat menggunakannya untuk keuntungannya dalam belajar (Jaleel dan Thomas, 2019). Berdasarkan hal tersebut, seorang dosen sangat perlu untuk mengetahui kecenderungan gaya belajar mahasiswanya. Sesuai dengan pendapat Jaleel dan Thomas (2019) bahwa Pengetahuan tentang gaya belajar seseorang sangat penting karena membantu seseorang menjadi lebih produktif dan kreatif, meningkatkan prestasi, meningkatkan keterampilan pemecahan masalah, membuat keputusan yang lebih baik, dan belajar lebih efektif. Dengan demikian, seorang dosen harus mampu memfasilitasi mahasiswa dengan berbagai model, strategi, metode atau media pembelajaran agar setiap gaya belajar dapat mengoptimalkan proses belajarnya. 


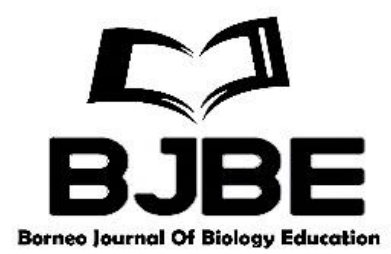

Vol. 2 No. 1, 2020; pp. 1-6

P-ISSN: 2715-6826 (print); E-ISSN: 2714-6073 (online)

Received: 25/01/2020

Revised: 15/02/2020

Accepted: 3/03/2020

\section{Kesimpulan}

Kesimpulan dari penelitian ini yaitu terdapat lima jenis kecenderungan gaya belajar mahasiswa baru jurusan Pendidikan biologi FKIP UBT, yaitu gaya belajar visual $(46,67 \%)$, auditorial (30\%), kinestetik $(8,33 \%)$, visual-auditorial $(11,67)$, dan visual kinestetik $(3,33 \%)$. Setiap gaya belajar tersebut memiliki keunikan masing-masing dalam menerima dan mengolah materi perkuliahan, sehingga dosen perlu untuk memfasilitasi setiap gaya belajar yang ada agar mahasiswa dapat memperoleh hasil belajar yang baik.

\section{Daftar Pustaka}

Deporter, B, dan Henarcki. (2010). Quantum Learning Membiasakan Belajar Nyaman dan Menyenangkan. Bandung: Kaifa

Deporter, B. \& Hernacki, M. (1992). Quantum Learning: Unleashing the Genius in You. Terjemahan oleh Alwiyah Abdurrahman (Quantum Learning: Membiasakan Belajar Nyaman dan Menyenangkan). 2009. Bandung: Kaifa.

Ghufron, M. N dan Risnawita, R. (2013). Gaya Belajar: Kajian Teorik. Yogyakarta: Pustaka Pelajar.

Jaleel, S. dan Thomas, A. M. (2019). Learning Styles - Theories and Implications for Teaching Learning. Horizon Research Publishing.

Jatikusumo, G. A., Mayangsari, T., Kurniadi, E. (2017). Analisis Gaya Belajar Siswa Sekolah Menengah Pertama Negeri 5 Kota Madiun. Prosiding Seminar Nasional Pendidikan Fisika III, 213-217.

Julianti, I. A. R. (2016). Analisis Karakteristik Gaya Belajar Siswa dalam Pembelajaran IPS Kelas V SDN Di Kecamatan Godong Kabupaten Grobogan. Skripsi. Universitas Negeri Semarang.

Subini, N. (2011). Rahasia Gaya Belajar Orang Besar. Jakarta: PT. Buku Kita.

Suparman. (2010). Gaya Mengajar yang Menyenangkan Siswa. Yogyakarta: Pinus BOOK Publisher.

Widayah, S. N. (2016). Pengaruh Gaya Belajar Siswa Terhadap Hasil Belajar Pendidikan Kewarganegaraan Di Sdn Gugus Dr. Cipto Mangunkusumo Kabupaten Pati. Skripsi. Universitas Negeri Semarang.

Zahroh, U dan Asyhar, B. (2014). Kecenderungan Gaya Belajar Mahasiswa dalam Menyelesaikan Masalah Fungsi Bijektif. Jurnal Kebijakan dan Pengembangan Pendidikan, 2 (1), 72-81. 